\title{
Magnesium Removal from Concentrated Nickel Solution by Solvent Extraction Using Cyanex 272
}

\author{
Zhu Zhaowu ${ }^{1,2}$, Zhang Jian ${ }^{1,2}$, Yi Aifei ${ }^{1,2}$, Su Hui ${ }^{1,2,3}$, Wang Lina ${ }^{1,2}$, Qi Tao ${ }^{1,2}$ \\ ${ }^{1}$ Hydrometallurgy Clean Production Technology National Engineering Laboratory, Institute of Process Engineering Chinese Academy of \\ Science, Beijing, China \\ ${ }^{2}$ Key Laboratory of Green Process and Engineering Chinese Academy of Science, Beijing, China \\ ${ }^{3}$ School of Chemistry and Chemical Engineering, University of Chinese Academy of Sciences, Beijing, China
}

Email address:

zhwzhu@ipe.ac.cn (Zhu Zhaowu), Linawang@ipe.ac.cn (Wang Lina), tqi@ipe.ac.cn (Qi Tao)

\section{To cite this article:}

Zhu Zhaowu, Zhang Jian, Yi Aifei, Su Hui, Wang Lina, Qi Tao. Magnesium Removal from Concentrated Nickel Solution by Solvent Extraction Using Cyanex 272. International Journal of Mineral Processing and Extractive Metallurgy. Vol. 4, No. 2, 2019, pp. 36-43.

doi: 10.11648/j.ijmpem.20190402.11

Received: May 4, 2019; Accepted: June 10, 2019; Published: June 25, 2019

\begin{abstract}
The refinery of mixed hydroxide precipitate (MHP) from nickel laterite processing by acidic re-leaching will generate a concentrated nickel solution containing some magnesium difficult to remove. Fluorite precipitation method is often used for nickel purification from magnesium contamination, causing serious risk of environmental pollution. Solvent extraction technology has obvious advantages in metal separation and purification which has been widely used in nickel cobalt industries. Magnesium separation from nickel in a synthetic re-leach solution by solvent extraction using Cyanex 272 (bis $(2,4$, 4-trimethylpentyl) phosphinic acid)) and its analogue of P 507 (2-ethylhexyl phosphonic acid mono-2-ethylhexyl ester) was studied. It was found that the separation factor of magnesium over nickel reached higher than 200 at $\mathrm{pH} 5.5$, which is much better than that of $\mathrm{P} 507$ with the maximum separation factor of 88 at $\mathrm{pH} 5.0$. The conditions including equilibrium $\mathrm{pH}$, organic concentration and $\mathrm{A} / \mathrm{O}$ ratio for metal extraction and separation of $\mathrm{Mg}$ and $\mathrm{Ca}$ from nickel with Cyanex 272 in a concentrated synthetic nickel solution were optimized. A five-stage counter-current batch continuous test was carried out with Cyanex 272 under optimized conditions. More than $99 \%$ of the magnesium was removed from the synthetic solution containing $3.4 \mathrm{~g} / \mathrm{L} \mathrm{Mg}$ and $106 \mathrm{~g} / \mathrm{L} \mathrm{Ni}$ using $0.5 \mathrm{M}$ Cyanex 272, leaving only $38 \mathrm{mg} / \mathrm{L} \mathrm{Mg}$ in the purified nickel solution, which is suitable for the electrowinning.
\end{abstract}

Keywords: Solvent Extraction, Cyanex 272, MHP, Magnesium, Nickel

\section{Introduction}

Nickel laterites account for about $60 \%$ of nickel resources, which are becoming the major sources for nickel production due to the depletion of nickel sulphite deposits [1, 2]. Two hydrometallurgical routes are commonly used for nickel laterite processing. One is high pressure acid leaching and another is heap leaching [2-5]. After leaching, hydroxide precipitation is used in a number of practices to produce nickel/cobalt mixed hydroxide precipitates (MHP) as intermediate products due to the low cost and easy reagent availability [6-8]. Magnesium oxide is commonly used for MHP precipitation [9], although other alkaline reagents such as $\mathrm{NaOH}$ and $\mathrm{Na}_{2} \mathrm{CO}_{3}$ were also used [10]. Since hydroxide precipitation has poor selectivity, MHP usually contains large amounts of impurities with concentrations varied depending on factors such as compositions of leach solutions, reagents used for the precipitation and leaching conditions. The main metals in $\mathrm{MHP}$ are $\mathrm{Ni}, \mathrm{Co}, \mathrm{Mn}, \mathrm{Mg}$ and some other impurities in a relatively low concentration, including $\mathrm{Fe}, \mathrm{Al}$, $\mathrm{Cu}$ and $\mathrm{Ca}[6,11]$.

MHP re-leaching will be conducted to produce a concentrated nickel solution which is subjected to electrowinning for nickel cathode production after purification. Ammonia/ammonium solution could be used to re-leach MHP to recover nickel and cobalt due to its high selectivity [12]. However, it suffers from some drawbacks of low nickel/cobalt recovery, high sensitivity to MHP aging time, significant loss of ammonium and difficulty in cobalt 
separation from nickel [13]. Acidic leaching is more preferred and commonly used due to its high efficiency [14]. In acidic leach solutions, if small amounts of Fe (III), Al, Cr (III) and $\mathrm{Cu}$ present, they can be readily removed by selective precipitation via $\mathrm{pH}$ adjustment to 4-5 [15]. Cobalt can be separated from nickel by solvent extraction with Cyanex 272 or P 507 (2-ethylhexyl phosphonic acid mono-2-ethylhexyl ester). Other impurities including $\mathrm{Mn}, \mathrm{Zn}$ and $\mathrm{Ca}$ if exist can be removed by solvent extraction using D2EHPA (Di-2-ethylhexyl phosphoric acid) [16].

A nickel selective acidic re-leach process of MHP was developed by Williams et al. [17]. In this process, sodium peroxy-disulphate was used to oxidize cobalt to Co (III) and manganese to Mn (IV) to suppress their leaching. More than $90 \%$ of nickel was preferentially extracted at $\mathrm{pH} 4.5$, while few impurities entered into the leach solution, and thus significantly enhanced the selectivity of acidic leaching with the resultant solution, typically containing (g/L): $\mathrm{Ni} 90, \mathrm{Mg} \mathrm{3}$, $\mathrm{Zn} 0.5, \mathrm{Ca} 0.1$ and trace amounts of $\mathrm{Co}, \mathrm{Mn}, \mathrm{Cu}, \mathrm{Fe}, \mathrm{Cr}$ and $\mathrm{Al}(<10 \mathrm{mg} / \mathrm{L})$. The leach efficiency was not affected by the aging time of the MHP up to four years. Cobalt in the leach residue was recovered in a separate reductive leach process using sodium metabisulphite acidified in sulfuric acid solution in $\mathrm{pH}$ range of 2-2.5 [18].

In concentrated nickel re-leached solutions, magnesium was usually in a high concentration which can significantly impact nickel electrowinning. It is difficult to be removed using conventional methods such as solvent extraction and ion exchange [19]. Therefore, fluoride precipitation was usually used to purify nickel solution from magnesium contamination to meet the electrowinning requirement [20]. The application of fluoride not only can contaminate the nickel product, but also has the risk of environmental pollution. Solvent extraction using P507 (same active component with P 507) has been investigated to separate magnesium and calcium from a nickel solution. Good separation of nickel from the calcium was obtained at $\mathrm{pH} 4.5$ $[21,22]$. However magnesium separation from nickel was very poor. When magnesium extraction was approximately $40 \%$ at the optimized $\mathrm{pH}$ of 6.0 , nickel extraction reached high of $10 \%$, resulting in a poor separation factor of 6 . A mixtures of Cyanex 272 (bis (2, 4, 4-trimethylpentyl) phosphinic acid)) with Versatic 10 (neodecanoic acid) or D2EHPA were also investigated [22, 23]. As nickel can be strongly extracted with Versatic 10 and D2EHPA, the separation nickel from magnesium with these mixtures was also very poor. In this study, the application of Cyanex 272 was evaluated to separate magnesium from nickel in order to purify nickel solution for the electrowinning purpose.

\section{Experimental}

\subsection{Reagents and Solution Preparation}

Cyanex 272 (industrial grade) and P507 (2-ethylhexyl phosphonic acid mono-2-ethylhexyl ester, 96\% purity) were provided by Cytec Industries Inc. (Shanghai, China) and
Laiyashi company (Shanghai, China), respectively, and used as received. Escaid 110, an aliphatic hydrocarbon solvent purchased from Exxon Mobil Corporation (Shanghai China agent) was used as the diluent. Organic solutions were prepared by dissolving extractants into the diluent to desired concentrations. A synthetic leach solution of MHP containing $106 \mathrm{~g} / \mathrm{L} \mathrm{Ni}$ and $3.4 \mathrm{~g} / \mathrm{L} \mathrm{Mg}$ was prepared by dissolving their corresponding metal sulfates (analytical grade) in de-ionized water. The final $\mathrm{pH}$ of the synthetic leach solution was adjusted to $5.0 \pm 0.05$ using lime (analytical grade). As a result of the $\mathrm{pH}$ adjustment, a calcium concentration of $0.6 \mathrm{~g} / \mathrm{L}$ was introduced into the synthetic solution. The solid residue of lime in the synthetic solution was removed by filtration.

\subsection{Procedures of Batch Extraction}

\subsubsection{Metal Extraction pH Isotherms}

Batch tests of metal extraction $\mathrm{pH}$ isotherms were conducted in $300 \mathrm{~mL}$ hexagonal glass jars immersed in a temperature controlled water bath at $40^{\circ} \mathrm{C}$. Equal volumes $(100 \mathrm{~mL})$ of the aqueous and organic solutions were added into the jar and mixed using an overhead stirrer connected with a $40 \mathrm{~mm}$ diameter impeller. After the temperature reached $40^{\circ} \mathrm{C}$, a solution containing $200 \mathrm{~g} / \mathrm{L} \mathrm{NaOH}$ was used to adjust the $\mathrm{pH}$. The $\mathrm{pH}$ was monitored using a ROSS Sure FlowpH probe (model 8127BN) connected to a Hanna portable $\mathrm{pH}$ meter (model HI9025). The mixture samples of $20 \mathrm{~mL}$ were taken using a syringe with a plastic extension at each desired $\mathrm{pH}$ point after the $\mathrm{pH}$ was constant for $2 \mathrm{~min}$ The two phases were separated using Whatman1PS filter paper. Aqueous solutions were then filtered again using membrane syringe filters with the pore size of $20 \mu \mathrm{m}$ to completely remove the entrained organic and metal concentrations were analyzed by ICP-AES (Inductively coupled plasma atomic emission spectroscopy, Varian). Organic solutions were stripped with $100 \mathrm{~g} / \mathrm{L} \mathrm{H}_{2} \mathrm{SO}_{4}$ at an $\mathrm{A} / \mathrm{O}$ ratio of $1: 1$ and $40^{\circ} \mathrm{C}$. The loaded strip liquors were then filtered and metal concentrations were analyzed by ICP-AES.

\subsubsection{Effect of Organic Concentration}

Equal volumes $(20 \mathrm{~mL})$ of the aqueous and organic solutions were mixed in a $100 \mathrm{~mL}$ hexagonal glass jar using an overhead stirrer connected with a $30 \mathrm{~mm}$ diameter impeller at $40^{\circ} \mathrm{C}$. The $\mathrm{pH}$ was adjusted to 5.50 using a solution containing $200 \mathrm{~g} / \mathrm{L} \mathrm{NaOH}$. Both aqueous and organic samples were prepared for analysis as aforementioned. The best performed organic solution composition was selected for further tests.

\subsubsection{Effect of $A / O$}

To determine the effect of $\mathrm{A} / \mathrm{O}$ ratio on the metal extraction and separation, different volumes of the aqueous synthetic solution and the organic solution were mixed in hexagonal jars at $40^{\circ} \mathrm{C}$ with final $\mathrm{pH}$ adjusted to 5.50. The two phases were separated and samples were prepared for analysis as mentioned above. 


\subsection{Extraction Kinetics}

For the determination of extraction kinetics, a preliminary extraction test was conducted with $0.5 \mathrm{M}$ Cyanex 272 solution and the synthetic aqueous solution at an $\mathrm{A} / \mathrm{O}$ ratio of $1: 1,40^{\circ} \mathrm{C}$ and $\mathrm{pH} 5.5$ to measure the amount of $\mathrm{NaOH}$ solution required for pre-equilibration. After that, the organic solution was pre-saponified with the measured amount of $\mathrm{NaOH}$ solution to obtain a similar end $\mathrm{pH}$ value. The synthetic aqueous solution and the pre-saponified organic solution were then mixed at an $\mathrm{A} / \mathrm{O}$ ratio of $1: 1$ and $40^{\circ} \mathrm{C}$. Samples of the mixed solution were taken at 0.5, 1.0, 1.5, 2.0, 3.0, 5.0 and $10 \mathrm{~min}$ for assay.

\subsection{Batch Continuous Extraction}

A five-stage batch continuous extraction test was carried out in $100 \mathrm{~mL}$ hexagonal glass jars immersed in a temperature controlled water bath at $40^{\circ} \mathrm{C}$. The two phases were mixed for 5 min using an overhead stirrer. To avoid the possibility of nickel sulfate crystallization via build-up in the middle stages, organic solution was inlet in two stages (EX5 and EX2) as shown in Figure 1. The phase ratio (A/O) was 1:1 in EX1 and EX2 and 2:1 in the stages EX3-5 (Figure 1). The organic solution consisting of $0.5 \mathrm{M}$ Cyanex 272 in Escaid 110 was pre-loaded with $9.2 \mathrm{~g} / \mathrm{L} \mathrm{Ni}$ to maintain the required $\mathrm{pH}$ and avoid introducing other impurities via $\mathrm{pH}$ adjustment. The pre-loaded organic solution was prepared by contacting the organic solution with an aqueous solution containing $30 \mathrm{~g} / \mathrm{L} \mathrm{Ni}$ at $\mathrm{pH} 6.0, \mathrm{~A} / \mathrm{O}$ of $2: 1$ and $40^{\circ} \mathrm{C}$. Both aqueous and organic solutions were pre-heated to $40^{\circ} \mathrm{C}$. The test was continued for 15 contact rows when the metal concentrations in the raffinate were almost constant (Figure 1). Mixed solutions were sampled, prepared and analyzed.

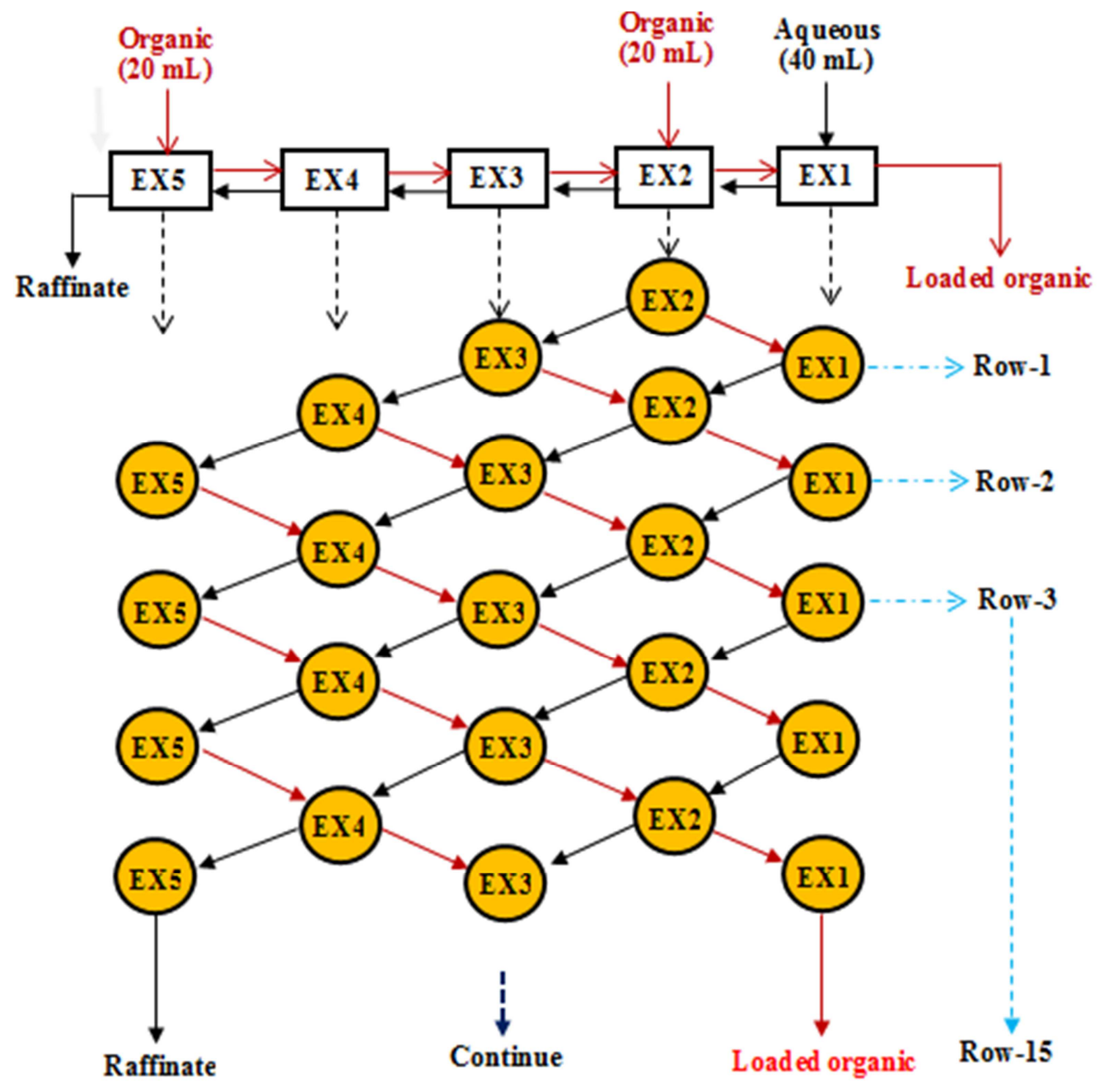

Figure 1. A schematic flowsheet of the batch continuous test.

\section{Results and Discussion}

\subsection{Metal Extraction pH Isotherms with Cyanex 272 and $P$ 507}

Cyanex 272 and P 507 are analogues of acidic phosphorus extractants which are commonly used for nickel and cobalt separation. Both extract calcium and magnesium stronger than nickel with very different separation efficiencies. Minor calcium can be readily removed from nickel solution by D2EHPA (Di-(2-ethylhexyl) phosphoric acid), another acidic phosphorus extractant [16], due to their high separation 
efficiency. However magnesium separation from nickel is poor, resulting in difficulty in its removal. To search the capability of magnesium removal using Cyanex 272 and $\mathrm{P}$ 507, Metal extraction $\mathrm{pH}$ isotherms were obtained using 0.5 M Cyanex 272 (Figure 2) and 0.5 M P 507 (Figure 3) organic solutions and a synthetic concentrated nickel solution.

High magnesium extraction was obtained in the $\mathrm{pH}$ range of 5.5-6.0 with the highest extraction of $85 \%$ at $\mathrm{pH} 5.5$ with 0.5 M Cyanex 272 system. Less than $5.3 \%$ of nickel was extracted in the $\mathrm{pH}$ range tested, leading to a good separation of magnesium from nickel as shown in Figure 2. Slight decrease in magnesium extraction with the $\mathrm{pH}$ increase from 5.5 to 6.0 might be attributed to the competitive extraction of nickel. The extraction of nickel slightly increased from near zero to $2.5 \%$ when $\mathrm{pH}$ increased from 4.0 to 5.5 , and then more rapidly to $5.3 \%$ as the $\mathrm{pH}$ increased to 6.0 . As slight increase in nickel extraction can lead to a significant increase in nickel loading in the organic solution due to its high concentration in the aqueous feed $(106 \mathrm{~g} / \mathrm{L})$, it is important to control nickel extraction to a low level. For example, 2.65 $\mathrm{g} / \mathrm{L}$ nickel was loaded in the organic solution at $\mathrm{pH} 5.5$ with the extraction of $2.5 \%$, and increased to $5.62 \mathrm{~g} / \mathrm{L}$ with the extraction of $5.3 \%$ at $\mathrm{pH} 6.0$. The extraction of calcium was low, varying from $8 \%$ to $14 \%$ in the $\mathrm{pH}$ range of $4.0-5.5$, and finally reached $20 \%$ at $\mathrm{pH} 6.0$. It is suggested that calcium is difficult to remove from the solution using Cyanex 272 system. Low calcium extraction favors to avoid the risk of gypsum formation by accumulation [24, 25]. Calcium, if exist, can be removed by solvent extraction with D2EHPA as discussed previously.

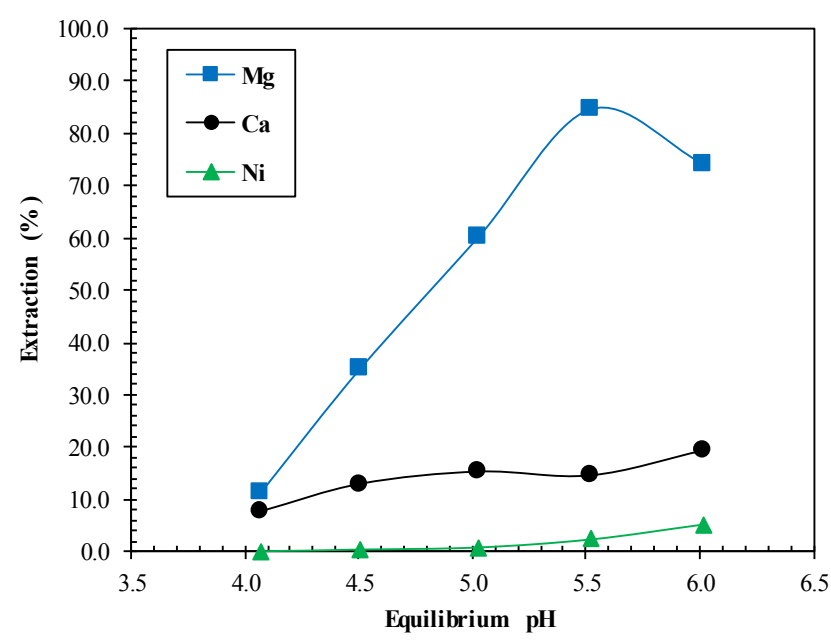

Figure 2. Metal extraction pH isotherms with 0.5 M Cyanex 272 organic solution.

The extraction of magnesium with $0.5 \mathrm{M}$ P 507 organic system (Figure 3) was higher than those obtained with $0.5 \mathrm{M}$ Cyanex 272 organic system (Figure 2). For example, magnesium extraction was $82 \%$ with the 0.5 M P 507 organic system at pH 5.0 compared to $56 \%$ using 0.5 M Cyanex 272 organic system. However, nickel extraction with the P 507 organic system was also significantly higher than that with the Cyanex 272 system, leading their poorer separation. At
$\mathrm{pH} 5.0$ and 5.5, nickel extraction reached 5\% and 10\% with the P 507 organic system, respectively, while they were only $2.5 \%$ and $5.3 \%$, respectively, with the Cyanex 272 organic system. The extraction of calcium was also stronger with $\mathrm{P}$ 507 than that with Cyanex 272. Unlike the extraction of magnesium and nickel, calcium extraction decreased with increasing $\mathrm{pH}$, indicating that the extraction was significantly suppressed by the competitive extraction of magnesium and nickel. As a result, maximum extractions of magnesium and calcium occurred at different $\mathrm{pH}$ values, resulting in the difficulty in their simultaneous removal from nickel using $\mathrm{P}$ 507 system, although some investigations have carried out for this purpose [21].

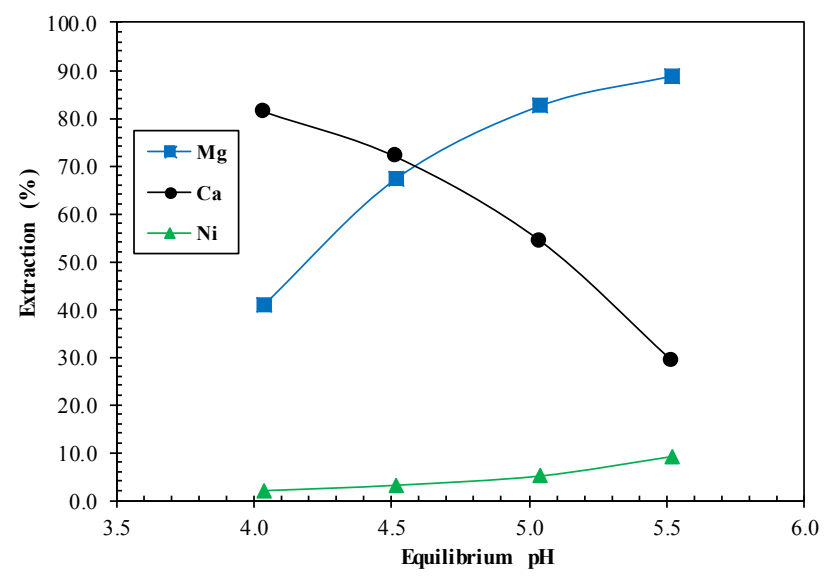

Figure 3. Metal extraction pH isotherms with 0.5 M P 507 organic solution.

Separation factors of magnesium and calcium over nickel $\left(\mathrm{SF}_{\mathrm{MgNi}}\right.$ and $\left.\mathrm{SF}_{\mathrm{Ca} / \mathrm{Ni}}\right)$ with $0.5 \mathrm{M}$ Cyanex 272 and $0.5 \mathrm{M}$ P 507 organic systems were calculated (Table 1). $\mathrm{SF}_{\mathrm{Mg} / \mathrm{Ni}}$ reached a maximum value of 215 at $\mathrm{pH} 5.5$ with Cyanex 272, and then decreased to 51 at $\mathrm{pH} 6.0$, indicating that appropriate $\mathrm{pH}$ control is vital to achieve good magnesium and nickel separation using Cyanex 272 system. With P 507 system, maximum $\mathrm{SF}_{\mathrm{Mg} / \mathrm{Ni}}$ was 88 at $\mathrm{pH} 5.0$, indicating that magnesium selectivity over nickel was poorer than that using Cyanex 272 system due to the higher nickel extraction. The largest separation factor of $\mathrm{SF}_{\mathrm{Ca} N \mathrm{Ni}}$ was 215 at $\mathrm{pH} 4.0$ where the separation factor of $\mathrm{SF}_{\mathrm{Mg} / \mathrm{Ni}}$ was only 34 , again, indicating that simultaneous separation of calcium and magnesium from nickel is difficult with P 507 system. Although the highest magnesium extraction was $89 \%$ with the P 507 system at pH 5.0 slightly higher than that of $86 \%$ with the Cyanex 272 system at $\mathrm{pH} 5.5$, Cyanex 272 is preferred for magnesium removal from nickel solutions due to its much better selectivity.

Table 1. Separation factors (SF) of magnesium and calcium over nickel with the two organic systems.

\begin{tabular}{lllll}
\hline \multirow{2}{*}{$\mathbf{p H}$} & Cyanex 272 & \multicolumn{3}{c}{$\mathbf{P 5 0 7}$} \\
\cline { 2 - 5 } & $\mathbf{S F}_{\mathbf{M g} / \mathbf{N i}}$ & $\mathbf{S F}_{\mathbf{C a} / \mathbf{N i}}$ & $\mathbf{S F}_{\mathbf{M g} / \mathbf{N i}}$ & $\mathbf{S F}_{\mathbf{C a} / \mathbf{N i}}$ \\
\hline 4.0 & 65 & 41 & 34 & 215 \\
4.5 & 104 & 29 & 63 & 78 \\
5.0 & 153 & 18 & 88 & 22 \\
5.5 & 215 & 3.5 & 78 & 4 \\
6.0 & 51 & 4.3 & - & - \\
\hline
\end{tabular}




\subsection{Effect of Cyanex 272 Concentration}

The effect of Cyanex 272 concentration on metal extractions was determined at $\mathrm{pH} 5.5$ and an $\mathrm{A} / \mathrm{O}$ ratio of $1: 1$ (Figure 4). All metal extractions increased with increasing Cyanex 272 concentration due to more extractant available. The extraction of magnesium was $32 \%$ and $62 \%$ with $0.14 \mathrm{M}$ and $0.27 \mathrm{M}$ Cyanex 272, respectively, while nickel extraction was negligible, indicating very good separation of magnesium from nickel. Significant amounts of nickel and calcium were extracted when Cyanex 272 concentration was increased to $0.81 \mathrm{M}$ and $1.08 \mathrm{M}$. Nickel and calcium extraction reached $7 \%$ and $30 \%$, respectively with $0.81 \mathrm{M}$ Cyanex 272 (Figure 4). According to the metal loading in the organic solution at different Cyanex 272 concentrations, organic used percentage by metal loading (Organic usage (\%) $=\left([\text { Metal }]_{\text {org. }} \times 2\right) /[$ Cyanex 272$\left.] \times 100\right)$ were calculated in Table 2. The organic used by magnesium was $63.7 \%$ and $63.4 \%$ at Cyanex 272 concentration of $0.13 \mathrm{M}$ and $0.25 \mathrm{M}$, respectively. It decreased to $42.7 \%$ when the Cyanex 272 concentration increased to $0.50 \mathrm{M}$. At the same time, the organic used by nickel and calcium extraction significantly increased. This suggested that high magnesium loading could strongly suppress the extraction of nickel and calcium. The separation factors of $\mathrm{SF}_{\mathrm{Mg} / \mathrm{Ni}}$ and $\mathrm{SF}_{\mathrm{Mg} / \mathrm{Ca}}$ under various Cyanex 272 concentrations are also given in Table 2. It can been seen that both $\mathrm{SF}_{\mathrm{Mg} / \mathrm{Ni}}$ and $\mathrm{SF}_{\mathrm{Mg} / \mathrm{Ca}}$ decreased with the increase in Cyanex 272 concentration, indicating that lowering Cyanex 272 concentration is favorable to the separation of magnesium from nickel and calcium.

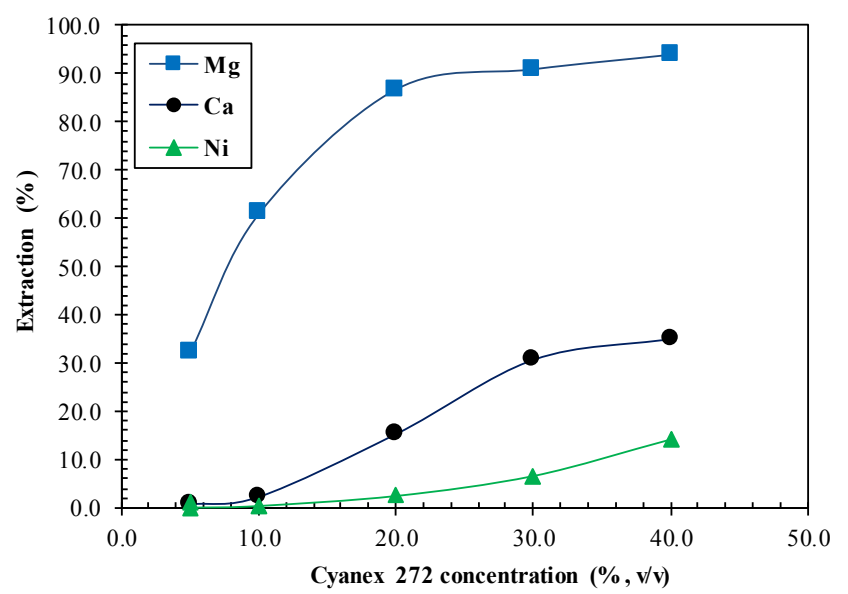

Figure 4. Effect of Cyanex 272 concentration on the metal extraction at $p H$ 5.5 .

Table 2. Organic usage by metal loading and separation factors (SF) at various Cyanex 272 concentrations.

\begin{tabular}{|c|c|c|c|c|c|c|c|c|c|}
\hline \multirow{2}{*}{$\begin{array}{l}\text { Concentration } \\
\text { (M) }\end{array}$} & \multicolumn{2}{|c|}{ Metal extraction (\%) } & \multicolumn{5}{|c|}{ Metal occupation (\%) } & \multirow{2}{*}{$\mathbf{S F}_{\mathbf{M g} / \mathbf{N i}}$} & \multirow{2}{*}{$\mathrm{SF}_{\mathrm{Mg} / \mathrm{Ca}}$} \\
\hline & Mg & $\mathrm{Ca}$ & $\mathrm{Ni}$ & Mg & $\mathrm{Ca}$ & $\mathrm{Ni}$ & Total & & \\
\hline 0.13 & 32.4 & 0.7 & 0.1 & 63.7 & 0.14 & 3.57 & 67.4 & 356 & 74 \\
\hline 0.25 & 61.1 & 2.3 & 0.5 & 63.4 & 0.25 & 6.05 & 69.7 & 336 & 69 \\
\hline 0.50 & 86.7 & 15.3 & 2.6 & 42.7 & 0.83 & 16.8 & 60.0 & 248 & 35 \\
\hline 0.75 & 90.8 & 30.7 & 6.7 & 29.7 & 1.11 & 28.4 & 59.2 & 138 & 21 \\
\hline 1.00 & 93.9 & 35.0 & 14.3 & 22.3 & 0.95 & 44.3 & 67.6 & 92 & 29 \\
\hline
\end{tabular}

$\left(\right.$ Organic usage $(\%)=\left([\text { Metal }]_{\text {org }}\right.$ X2)/[Cyanex 272] X100).

\subsection{Effect of A/O Ratio and McCabe Thiele Diagram}

Metal extractions under various $\mathrm{A} / \mathrm{O}$ ratios with $0.5 \mathrm{M}$ Cyanex 272 at pH 5.5 are shown in Figure 5. The extraction of the three metals increased with the decrease in $\mathrm{A} / \mathrm{O}$ ratio again due to the increase in extractant availability. Significant nickel and calcium were extracted when $\mathrm{A} / \mathrm{O}$ ratio was smaller than $2: 1$. At an $\mathrm{A} / \mathrm{O}$ ratio of $2: 1$, the extraction of nickel was negligible and calcium extraction was about $2 \%$, and then they rapidly increased to $35 \%$ and $64 \%$, respectively at $\mathrm{A} / \mathrm{O}$ ratio of $1: 4$ (Figure 5). The organic used percentage by metal loading and separation factors under various $\mathrm{A} / \mathrm{O}$ ratios are given in Table 3 . With the decrease in $\mathrm{A} / \mathrm{O}$ ratio, the percentage used by magnesium loading decreased, whereas used for nickel and calcium was increased. This is very similar to that by varying Cyanex 272 concentration as discussed previously. Clearly, it is suggested that more extractant available free from magnesium extraction will be largely used for the extraction of nickel and calcium, resulting in poorer separation of magnesium from them. Therefore, it is very important to well control the organic concentration or $\mathrm{A} / \mathrm{O}$ to limit excess extractant available for the nickel extraction.
For example, the highest $\mathrm{SF}_{\mathrm{Mg} / \mathrm{Ni}}$ was 279 at $\mathrm{A} / \mathrm{O}$ ratio of $2: 1$ and rapidly decreased to 74 at $\mathrm{A} / \mathrm{O}$ ratio of $1: 4$ (Table 3 ). Similarly, $\mathrm{SF}_{\mathrm{Mg} / \mathrm{Ca}}$ was 71 at $\mathrm{A} / \mathrm{O}$ ratio $2: 1$ and decreased to 21 at $\mathrm{A} / \mathrm{O}$ ratio of $1: 4$. Lowering $\mathrm{A} / \mathrm{O}$ ratio can avoid gypsum formation and nickel sulfate crystallization by limiting their extraction in a continuous process. The McCabe Thiele diagram of magnesium extraction is constructed and shown in Figure 6. It is indicated that three theoretical stages are required to almost completely extract the magnesium from the synthetic solution using $0.5 \mathrm{M}$ Cyanex 272 at $\mathrm{A} / \mathrm{O}$ of $1: 1$.

Table 3. Organic used percentage by metal loading with Cyanex 272 system and separation factors (SF) under various $\mathrm{A} / \mathrm{O}$ ratios.

\begin{tabular}{|c|c|c|c|c|c|c|}
\hline \multirow{2}{*}{$\mathbf{A} / \mathbf{O}$} & \multicolumn{4}{|c|}{ Organic used percentage (\%) } & \multirow{2}{*}{$\mathrm{SF}_{\mathrm{Mg} / \mathrm{Ni}}$} & \multirow{2}{*}{$\mathbf{S F}_{\mathbf{M g} / \mathrm{C} a}$} \\
\hline & Mg & $\mathrm{Ca}$ & $\mathbf{N i}$ & Total & & \\
\hline $4: 1$ & 69.2 & 0.11 & 6.56 & 75.8 & 221 & 107 \\
\hline $2: 1$ & 62.0 & 0.25 & 8.15 & 70.4 & 279 & 71 \\
\hline $1: 1$ & 42.7 & 0.83 & 16.5 & 60.0 & 236 & 33 \\
\hline $1: 2$ & 24.2 & 1.11 & 30.9 & 56.3 & 180 & 24 \\
\hline $1: 3$ & 16.7 & 1.05 & 36.8 & 54.5 & 136 & 18 \\
\hline $1: 4$ & 12.4 & 0.86 & 53.6 & 66.8 & 74 & 21 \\
\hline
\end{tabular}




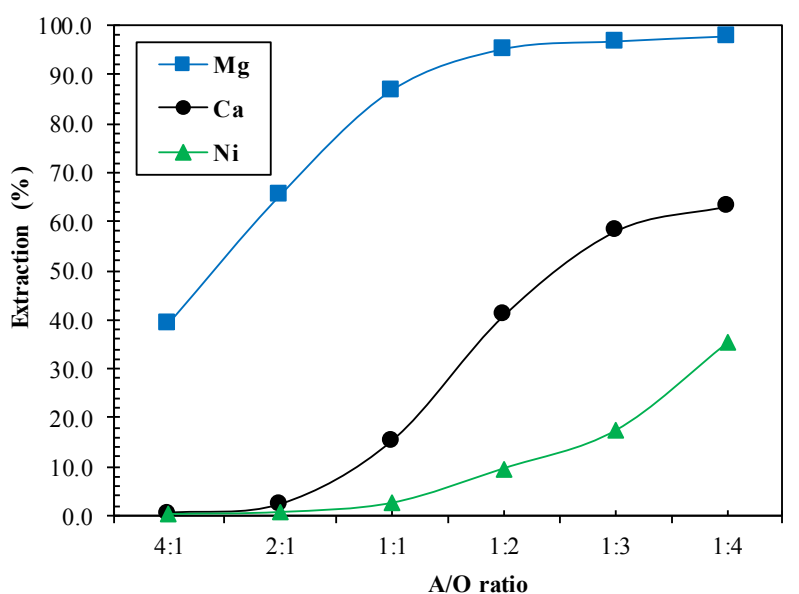

Figure 5. Effect of A/O ratio on metal extraction with 0.5 M Cyanex 272 at pH 5.5 .

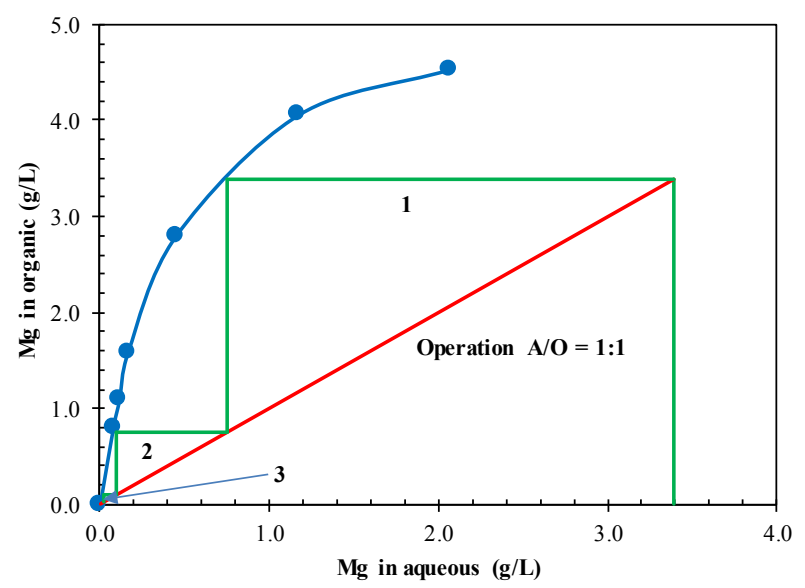

Figure 6. Magnesium extraction distribution isotherm and its McCabe Thiele diagram.

\subsection{Metal Extraction Kinetics}

Metal extraction kinetics was studied to determine the appropriate contact time for the continuous test (Figure 7). From Figure 7, it can be seen that all extractions of magnesium, calcium and nickel were fast, reaching equilibrium within $0.5 \mathrm{~min}$.

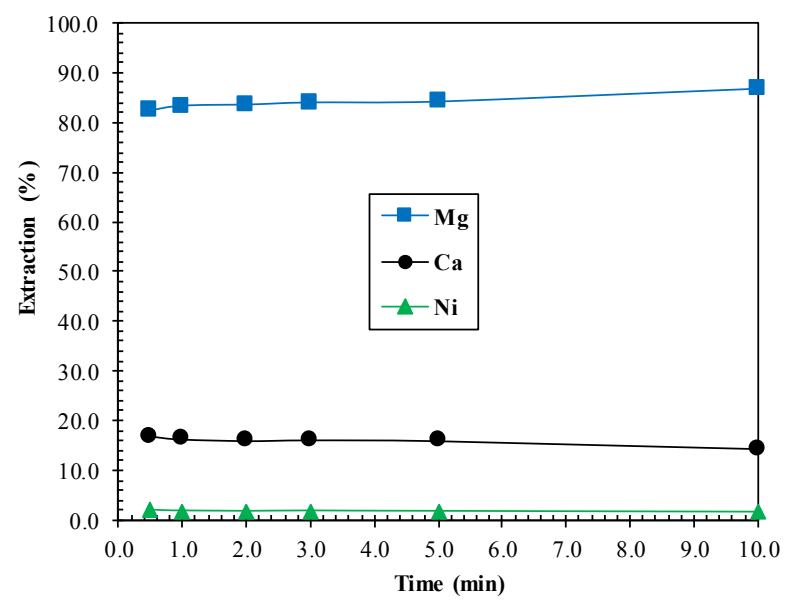

Figure 7. Metal extraction kinetics with 0.5 M Cyanex 272 at an $A / O$ ratio of $1: 1$ and $40^{\circ} \mathrm{C}$.

\subsection{Batch Continuous Test}

According to the McCabe Thiele diagram (Figure 6), magnesium can be completely extracted from the synthetic solution in three theoretical stages with $0.5 \mathrm{M}$ Cyanex 272 at $\mathrm{A} / \mathrm{O}$ of $1: 1$. However, it is predicted that large amounts of nickel and calcium will be extracted in last stages due to lower magnesium concentration, leaving large amount of Cyanex 272 free for nickel and calcium extraction. This will result in the build-up of nickel and calcium in the middle stages, potentially leading to the risk of nickel sulfate crystallization and gypsum formation. To ensure efficient magnesium extraction and suppress nickel and calcium accumulation, five stages were used in the batch continuous test where a higher $\mathrm{A} / \mathrm{O}$ ratio of $2: 1$ was used in the last three stages (as shown in Figure 1). A pre-loaded organic solution containing $9.2 \mathrm{~g} / \mathrm{L}(0.16 \mathrm{M})$ $\mathrm{Ni}$ was used. It was 1.1 times stoichiometrically of the amount required for the exchange with $3.4 \mathrm{~g} / \mathrm{L}(0.14 \mathrm{M})$ $\mathrm{Mg}$ in the synthetic solution. As reported elsewhere [26], nickel pre-loaded organic solution was used to avoid the introduction of other impurities via $\mathrm{pH}$ adjustment using base. During the test, the extraction $\mathrm{pH}$ in each stage was well maintained in a range of 5.5-5.7 without adding alkaline solution for the $\mathrm{pH}$ adjustment. Metal extraction distribution profiles in the organic and aqueous phases are shown in Figures 8 and 9, respectively. A rapid increase in magnesium concentration from EX3 to EX2 then to EX1was observed in the organic phase (Figure 8), suggesting that significant magnesium extraction occurred in EX1 and EX2. Magnesium concentration in aqueous phase decreased rapidly from the feed to EX1 and then to EX2 as shown in Figure 9. Magnesium concentration in discharged nickel solution (EX5 aqueous phase) was 38 $\mathrm{mg} / \mathrm{L}$ which could meet the requirement of nickel electrowinning [19]. This corresponds to $98.9 \%$ of magnesium extraction over five stages.

Nickel concentration in the organic phase increased slightly from the feed organic to EX5, then gradually decreased from EX5 to EX2, and finally decreased rapidly to EX1 (Figure 9). This indicated that a small amount of nickel was extracted in stage 5, then the pre-loaded nickel was gradually exchanged with magnesium, and stripped to the aqueous phase. Significant exchange between nickel and magnesium occurred from EX2 to EX1 which was consistent with the magnesium extraction (Figure 8). Nickel in EX1 organic phase was approximately $2 \mathrm{~g} / \mathrm{L}$ (Figure 8) and will be discharged together with the magnesium. The discharged nickel can be recycled by scrubbing. There was no obvious build-up of nickel in any stages owing to the higher $\mathrm{A} / \mathrm{O}$ ratio used in the last three stages. Calcium concentration distributions were near flat in both organic and aqueous phases, indicating that no calcium build-up occurred, effectively inhibiting gypsum formation. Therefore, no gypsum formation was observed during the continuous test. 


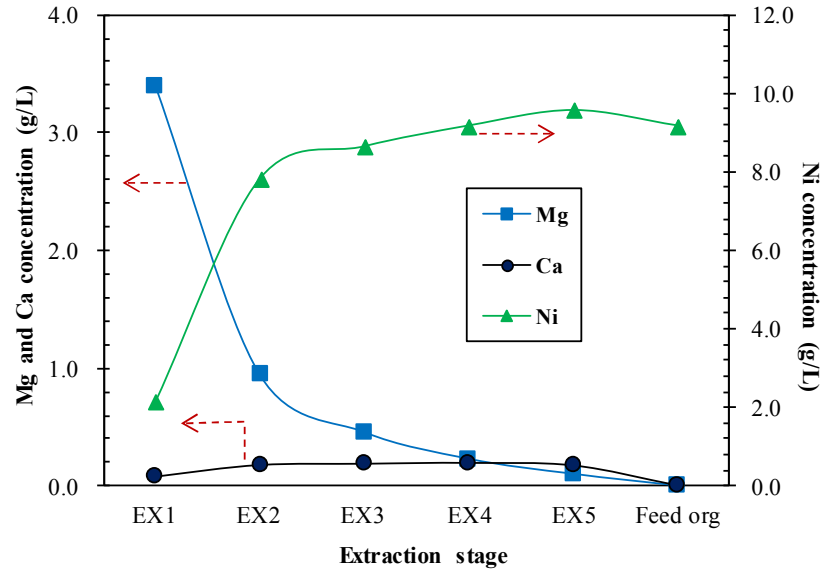

Figure 8. Metal extraction distribution profile in the organic phase.

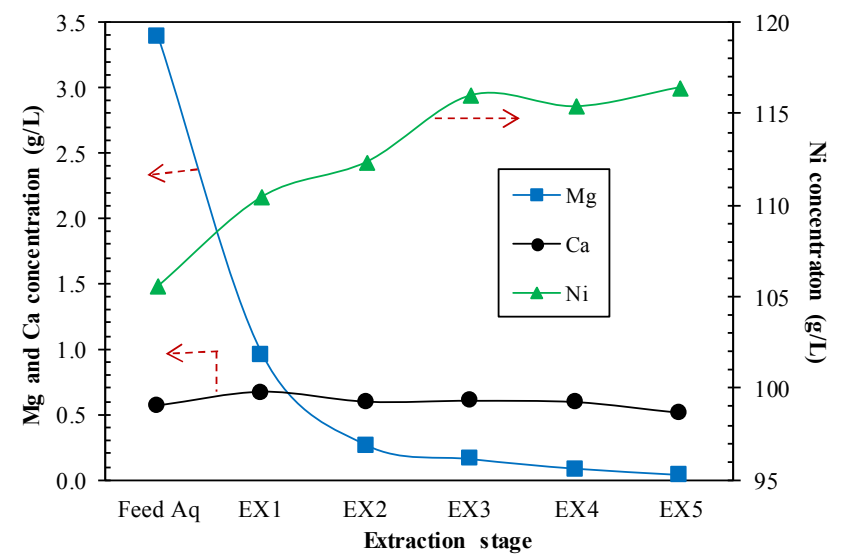

Figure 9. Metal extraction distribution profile in the aqueous phase.

\section{Conclusions}

Magnesium can be readily removed by solvent extraction using Cyanex 272 to meet the requirement of nickel electrowinning. It should be very useful for magnesium removal from a concentrated nickel solution usually obtained from MHP (mixed hydroxide precipitation) treatment during nickel laterite processing. Unlike the conventional method by fluorite precipitation, solvent extraction method using Cyanex 272 for nickel purification from magnesium contamination could avoid the risk of environmental pollution. The separation factor of magnesium over nickel with Cyanex 272 reached $>200$, much better than its analogue of $\mathrm{P}$ 507. The optimized $\mathrm{pH}$ for magnesium extraction with Cyanex 272 was 5.5 with very low extraction of nickel and calcium. In a batch continuous operation, nearly $99 \% \mathrm{Mg}$ was removed from the synthetic re-leach solution in five-stages extraction at an $\mathrm{A} / \mathrm{O}$ ratio of $1: 1$ for the first two stages and 2:1 for the last three stages, leaving less than $50 \mathrm{mg} / \mathrm{L} \mathrm{Mg}$ in the purified nickel solution.

\section{Acknowledgements}

The authors would like to acknowledge the financial support by National Natural Science Foundation of China
(51774260) and the Key Research Program of Frontier Sciences of Chinese Academy of Sciences (Grant No. QYZDJ-SSW-JSC021).

\section{References}

[1] S. Farrokhpay, and L. Filippov (2016). Challenges in processing nickel laterite ores by flotation. International Journal of Mineral Processing 151, 59-67.

[2] K. Komnitsas, E. Petrakis, G. Bartzas, and V. Karmali (2019). Column leaching of low-grade saprolitic laterites and valorization of leaching residues. Science of the Total Environment, 665, 347-357.

[3] S. Kursunoglu, and M. Kaya, (2016). Atmospheric pressure acid leaching of Caldag lateritic nickel ore. International Journal of Mineral Processing, 150, 1-8.

[4] A. Oxley, M. E. Smith, and O. Caceres (2016). Why heap leach nickel laterites? Minerals Engineering, 88, 53-60.

[5] H. Basturkcu, N. Acarkan, and E. Gock (2017). The role of mechanical activation on atmospheric leaching of a lateritic nickel ore. International Journal of Mineral Processing, 163, $1-8$.

[6] R. Harvey, R. Hannah, and J. Vaughan (2011). Selective precipitation of mixed nickel-cobalt hydroxide. Hydrometallurgy, 105, 222-228.

[7] C. H. Kose, and Y. A. Topkaya (2011). Hydrometallurgical processing of nontronite type lateritic nickel ores by MHP process. Minerals Engineering, 24, 396-415.

[8] K. Wang, J. Li, R. G. McDonald, and R. E. Browner (2018). Iron, aluminium and chromium co-removal from atmospheric nickel laterite leach solutions. Minerals Engineering, 116 (15), $35-45$.

[9] T. Treasure, and H. Muller (2011). Why make MHP. ALTA 2011 Nickel/Cobalt/Copper Conference, May 23-25, Perth, Australia.

[10] P. K. Anderson (2010). Mining development on the Kurumbukari Plateau in the Madang Province: Ramu Nico project [online]. Contemporary PNG Studies, 13, 95-114.

[11] L. Y. Wang, and M. S. Lee (2017). Separation of Co (II) and $\mathrm{Ni}$ (II) from chloride leach solution of nickel laterite ore by solvent extraction with Cyanex 301. International Journal of Mineral Processing, 166, 45-52.

[12] D. T. White (2009). Commercial development of the magnesia mixed hydroxide process for recovery of nickel and cobalt from laterite leach solutions. Hydrometallurgy of Nickel and Cobalt 2009, Proceedings of the $39^{\text {th }}$ Annual Hydrometallurgy Meeting, Ontario, Canada.

[13] A. N. Jones, and N. J. Welham (2010). Properties of aged mixed nickel-cobalt hydroxide intermediates produced from acid leach solutions and subsequent metal recovery. Hydrometallurgy, 103, 173-179.

[14] W. Geng, J. Zhang, G. You, T. Zhou, C. Ding, Y. Yang, R. Wang, X. Wei, Q. Li, L. Zhao, Y. Wu, and M. Zhao (2016). A separation technique to recover nickel and cobalt from a nickel hydroxide having high content of cobalt. Chinese patent, CN 105274332 A (in Chinese). 
[15] D. S. Flett (2004). Cobalt-nickel separation in hydrometallurgy: a review. Chemistry for Sustainable Development, 12, 81-91.

[16] J. Chang, F. Jia, C. Srinivasakannanb, K. A. Mumford, and X. Yang (2019). Impure ions removal from multicomponent leach solution of nickel sulfide concentrates by solvent extraction in impinging stream rotating packed bed. Chemical Engineering \& Processing: Process Intensification, 137, 54 63 .

[17] C. Williams, W. Hawker, and J. W. Vaughan (2013). Selective leaching of nickel from mixed nickel cobalt hydroxide precipitate. Hydrometallurgy, 138, 84-92.

[18] S. Chong, W. Hawker, and J. Vaughan (2013). Selective reductive leaching of oxidised cobalt containing residue. Minerals Engineering, 54, 82-87.

[19] S. K. Gogia, and S. C. Das, (1988). The effects of $\mathrm{Mg}^{2+}, \mathrm{Mn}^{2+}$, $\mathrm{Zn}^{2+}$, and $\mathrm{Al}^{3+}$ on the nickel deposit during electrowinning from sulphate bath. Metallurgical Transaction B, 19B, 823-830.

[20] G. A. Georgalli, J. J. Eksteen, M. Pelser, L. Lorenzen, M. S. Onyango, and C. Aldrich (2008). Fluoride based control of Ca and $\mathrm{Mg}$ concentrations in high ionic strength base metal sulphate solutions in hydrometallurgical circuits. Minerals Engineering, 21 (3), 200-212.

[21] J. Wang, and B. Li (2012). A solvent extraction method for calcium and magnesium removal, Chinese patent, $\mathrm{CN}$ 102417982A (in Chinese).
[22] A. S. Guimarães, and M. B. Mansur (2017). Solvent extraction of calcium and magnesium from concentrate nickel sulfate solutions using D2HEPA and Cyanex 272 extractants. Hydrometallurgy, 173, 91-97. A. S. Guimaraes, P. S. da Silva, and M. B. Mansur (2014). Purification of nickel from multicomponent aqueous sulfuric solutions by synergistic solvent extraction using Cyanex 272 and Versatic 10. Hydrometallurgy, 150, 173-177.

[23] A. S. Guimaraes, and M. B. Mansur (2015). Selective solvent extraction of calcium and magnesium from concentrate nickel solutions using Mixtures of Cyanex 272 and D2EHPA. World Academy of Science-Engineering and Technology, 34 (10), 1113-1118.

[24] J. S. Preston, and A. C. du Preez (2000). Separation of nickel and calcium by solvent extraction using mixtures of carboxylic acids and alkylpyridines. Hydrometallurgy, 58 (3), 239-250.

[25] S. Donegan (2006). Direct solvent extraction of nickel at Bulong operations. Minerals Engineering, 19 (12), 1234-1245.

[26] M. C. Olivier, C. Dorfling, and J. J. Eksteen (2012). Evaluating a solvent extraction process route incorporating nickel preloading of Cyanex 272 for the removal of cobalt and iron from nickel sulphate solutions. Minerals Engineering, 27, $37-51$. 